\title{
The Effect of Co-Saturated Salts on the Kinematic Viscosity of Water
}

\author{
Alexei A. Akoulov*, Travis Wiens*+1
}

\begin{abstract}
It is well documented in the literature how individual salts such as sodium chloride $(\mathrm{NaCl})$ and potassium chloride $(\mathrm{KCl})$ effect the kinematic viscosity of a water solution. However, there exists little to no information on how the presence of both $\mathrm{NaCl}$ and $\mathrm{KCl}$ in a co-saturated state affect the kinematic viscosity of the solution. This paper reviews experimental measurements of co-saturated aqueous $\mathrm{NaCl}: \mathrm{KCl}$ solutions across the temperature range of $20-65 \mathrm{OC}$ at three different concentration ratios. These data are compared to the known kinematic viscosity curves of saturated $\mathrm{NaCl}$ solution and pure water from literature.
\end{abstract}

Keywords: $\mathrm{NaCl}, \mathrm{KCl}$, co-saturation, kinematic viscosity, water, brine

\section{Introduction}

The effect of $\mathrm{KCl}$ or $\mathrm{NaCl}$ salts on the kinematic viscosity of water has been extensively measured and reported in literature by Kestin, Khalifa, and Correia (1981a, 1981b). In their works, they tabulated the kinematic viscosity of aqueous $\mathrm{NaCl}$ or $\mathrm{KCl}$ solutions as a function of temperature over the temperature range of $25-250 \mathrm{OC}$ and pressure range of 0.1-35 MPa. Unfortunately single-salt saturated solutions are not always used in practice and in the industry. A locally important example of this is in the mining sector where potash (mostly $\mathrm{KCl}$ and $\mathrm{NaCl}$ ) is extracted for argriculture, pharmaceuticals, food processeses and manufacturing textiles (Canpotex 2018). One method for reaching deep underground potash ore deposits is to use solution mining.
In solution mining, hot water is pumped underground into the ore body where the $\mathrm{NaCl}$ and $\mathrm{KCl}$ salt dissolve together into the water. The saturated brine mixture is then pumped back up to the surface for processing and distribution (Kay 2018). The benefits of solution mining over conventional mining is lower initial project costs, shorter construction phases, educed engineering risk, more extraction opportunities and higher operating efficiencies to name a few (Gensource Potash Corp n.d).

To properly model the salt brine in solution mining, the combined effects of both $\mathrm{NaCl}$ and $\mathrm{KCl}$ on the kinematic viscosity of water should be known. Indeed there exist some information on this matter in the literature. Correia, Kestin,

${ }^{1}$ Corresponding author and supervising professor

\footnotetext{
*Department of Mechanical Engineering, College of Engineering, University of Saskatchewan, Saskatoon, SK, Canada
}

+Correspondence: t.wiens@usask.ca 


\begin{tabular}{|c|c|c|c|c|c|}
\hline \multirow[t]{2}{*}{ Solution \# } & \multirow[t]{2}{*}{$\begin{array}{l}\text { Ratio of } \\
\mathrm{NaCl}: \mathrm{KCL}\end{array}$} & Total Molality & $\begin{array}{c}\text { Molality of } \\
\mathrm{NaCl}\end{array}$ & $\begin{array}{c}\text { Molality of } \\
\mathrm{KCL}\end{array}$ & \multirow[t]{2}{*}{$\begin{array}{c}\mathrm{NaCl} \text { concentration } \\
\mathrm{g} / \mathrm{ml}\end{array}$} \\
\hline & & \multicolumn{3}{|c|}{$\mathrm{mol} / \mathrm{kg} \mathrm{H}_{2} \mathrm{O}$} & \\
\hline 1 & 1:1 & 2.0096 & 1.0044 & 1.0052 & 0.059 \\
\hline 2 & 3:1 & 4.0037 & 3.0029 & 1.0008 & 0.175 \\
\hline 3 & $2: 2$ & 3.9951 & 1.9993 & 1.9958 & 0.116 \\
\hline 4 & $1: 3$ & 4.0518 & 1.0297 & 3.0221 & 0.060 \\
\hline
\end{tabular}

and Khalifa measured the dynamic viscosity of four aqueous $\mathrm{NaCl}: \mathrm{KCl}$ mixtures at $25,80,150 \mathrm{oC}$ in the pressure range 0.1$35 \mathrm{MPa}$ (1979). The mixture details are provided in Table 1. However the aqueous solutions they measured are not in a state of co-saturation but rather in a state of only partial saturation. This paper attempts to investigate how both $\mathrm{NaCl}$ and $\mathrm{KCl}$ in a co-saturated state affect the kinematic viscosity of water.

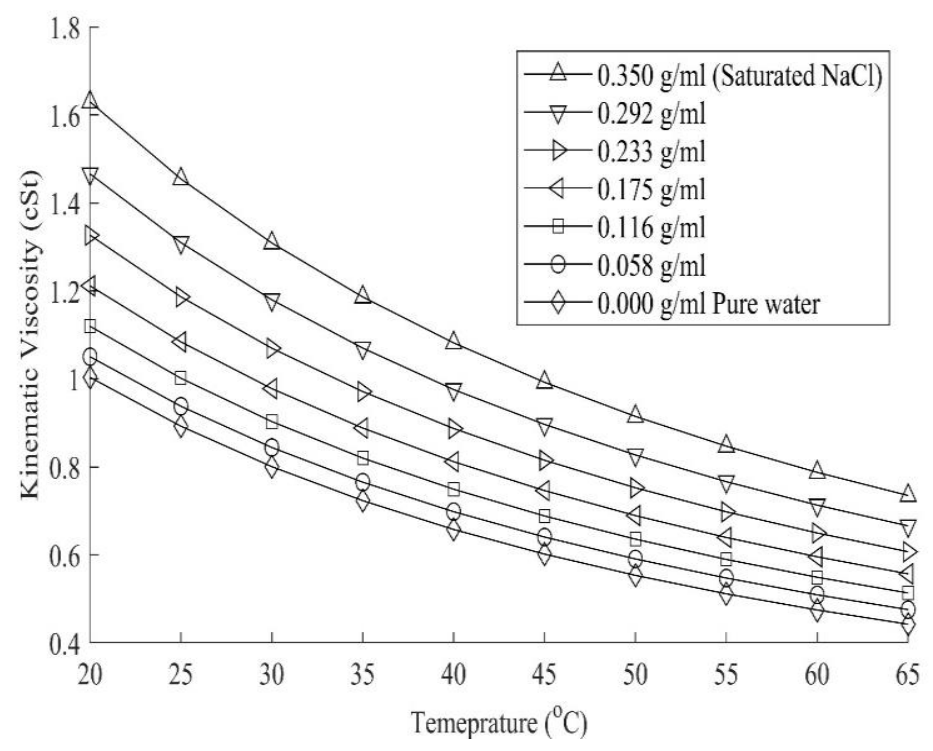

Figure 1: Kinematic viscosity of aqueous $\mathrm{NaCl}$ solution vs temperature. Each line represents a different concentration of $\mathrm{NaCl}$. Data collected from (Kestin, Khalifa, and Correia, 1981a).

\section{Effect of Individual Salts}

To provide a benchmark for how mutiple salts affect the kinematic viscosity of water, one should first look at the effect of single-salted solutions. Using tabulated data acquired by Kestin, Khalifa, and Correia (1981a), one is able to see how the kinematic viscosity of an aqueous $\mathrm{NaCl}$ solution changes with both temperature and concentration. In Figure 1 one can see that as the temperature of the $\mathrm{NaCl}$ solution increases, there is a decrease in the kinematic viscosity of the solution. Alternatively, if one increases the concentration of $\mathrm{NaCl}$ then there is an increase in the viscosity. Each $\mathrm{NaCl}$ curve in Figure 1 is distinct and independent from the rest; no overlap occurs between any of the curves.

However, it can be observed from Figure 2 that the effects of the presence of $\mathrm{KCl}$ salt exhibits less consistency and independence. Although an increase in temperature still led to decreased kinematic viscosity, it appears that the addition of $\mathrm{KCl}$ can either increase or decrease the viscosity of water depending on the temperature. At lower temperatures the $\mathrm{KCl}$ addition seems to decrease the viscosity of water while at higher temperatures one can see the reverse effect. It is notable to point out that there is considerable magnitude difference between the $\mathrm{NaCl}$ and $\mathrm{KCl}$ viscosity curves. $\mathrm{NaCl}$ appears to have an effect on viscosity that is 10 times greater than that of $\mathrm{KCl}$. One cannot help but speculate that when the salts are in a co-saturated state the dominating chloride compound will be that of sodium as it induces a greater change in viscosity. 




Figure 2: Kinematic viscosity of aqueous $\mathrm{KCl}$ solution vs temperature. Each curve represents a different concentration of $\mathrm{KCl}$. Data was collected from Kestin, Khalifa, and Correia (1981b).

Course Temperature Adjustment

Fine Temperature Adjustment



Aluminum Foil to minimize evaporation losses

Partially Submerged $50 \mathrm{ml}$ Glass Beaker

Blue Aluminum Scissor-Lift Stand

Figure 3: Temperature bath used to heat beaker samples of co-saturated salt solutions. 


\section{Procedure}

To measure the kinematic viscosity of co-saturated $\mathrm{NaCl}$ and $\mathrm{KCl}$ solutions directly over the temperature range of 20-65 oC, a Koehler KV3000 kinematic viscosity instrument was used. Note that readings were taken in order of decreasing temperature starting at $650 \mathrm{C}$. Three solutions were prepared containing both $\mathrm{KCl}$ and $\mathrm{NaCl}$ in $\mathrm{NaCl}: \mathrm{KCl}$ ratios of 1:1, 1.5:1 and 2:1. The experimental results, whose estimated uncertainty is $\pm 1 \%$, were collected and the kinematic viscosity was plotted against both temperature and concentration ratio. The experiment was performed at room temperature under atmospheric pressure (101.3 $\mathrm{KPa}$ ).

To ensure that both $\mathrm{NaCl}$ and $\mathrm{KCl}$ would dissolve relatively uniformly in water, care was taken to pre-mix the salts in solid form before they were poured into a water-filled test beaker. Once the necessary amounts of $\mathrm{NaCl}$ and $\mathrm{KCl}$ were measured and mixed in the proper proportions they were then poured slowy into a $50 \mathrm{ml}$ glass beaker containing $30 \mathrm{ml}$ of distilled water at $65 \mathrm{oC}$ until saturation occurred. To keep the beaker at a constant temperature a Brookfeild TC200 circulating temperature bath was used (see Figure 3 ). An aluminum scissor-lift stand helped to keep the beaker rim just above the reservoir water level. To prevent evaporative water loss during heating an aluminum foil cover was placed on the top of the beaker. Once fully saturated and heated, an automatic pipette was used to suction the right amount of fluid into an opaque Cannon-Fenske reverse-flow viscometer tube (see Figure 4). The Cannon-Fenske tube was inverted so as to draw the beaker fluid up to the fill line. The tube was then placed inside the temperature-controlled oil vat of a Koehler $\mathrm{KV}_{3} 3000$ instrument (see Figure 5).

To obtain a reading from the Koehler instrument, LCD display timers would be used to measure the time taken for the co-saturated solution to travel from the lower bulb start line to the lower bulb finish line (see Figure 4). Using the calibration constants found in Table 2 and performing a linear regression one is able to obtain the constants for each measured temperature value within our targeted temperature range of $20-650 C$. The elapsed time measured using the display timers would then be multiplied by an appropriate calibration constantto obtain the kinematic viscosity of the solution in terms of centistokes (cSt). Note that each temperature has a unique calibration constant obtained from the manufacturer.

\section{Results}

Figure 6 shows the resultant kinematic viscosity of the saturated $\mathrm{NaCl}: \mathrm{KCl}$ solutions at different ratios against temperature. The raw viscosity data can be found in Appendix A. One can see that it has similarly with the $\mathrm{NaCl}$ curves presented in Figure 1. Please note that in the interest of saving time during the experiment some intermediate data points in Figure 6 were not measured and do not appear in the figure. This curve resemblance between Figure 1 and Figure 6 makes sense as the effect of $\mathrm{KCl}$ on the viscosity of water is quite low. Therefore, the expected effect $\mathrm{KCl}$ has on a cosaturated sample should also be low, which appears to be the case in this study.

To fully appreciate the relationship between kinematic viscosity, temperature and the ratio of $\mathrm{NaCl}: \mathrm{KCl}$ it was necessary to plot viscosity against concentration ratio in Figure 7. One can see that there is a clear trend between the different temperature curves. Note that the curve-fits for $200 \mathrm{C}, 350 \mathrm{C}$ and $400 \mathrm{C}$ are omitted due to the lack of enough data points. However it is believed they follow a similar trend to the rest. The curve starts in a purely $\mathrm{KCl}$ saturated state and as expected the viscosity approaches a maximum value in the form of a horizontal asymptote. This viscosity limit in the graph occurs because of complete $\mathrm{NaCl}$ saturation of the solution.

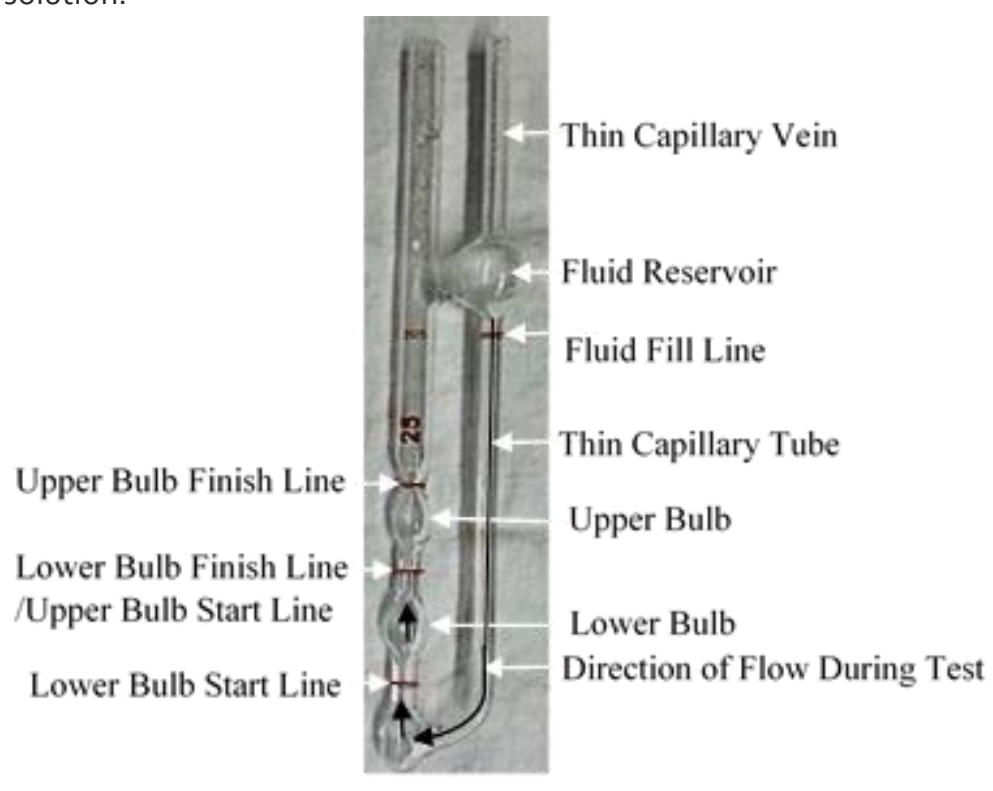

Figure 4: Diagram of Cannon-Fenske reverse-flow viscometer tube. Note the fluid begins in the fluid reservoir where it is pulled down by gravity and up the left glass column. 


\begin{tabular}{|c|c|c|c|c|c|c|}
\hline \multicolumn{7}{|c|}{ Table 2: Cannon-Fenske Opaque Viscometer Tube Calibration Constants } \\
\hline Size \# & $\begin{array}{c}\text { Tube ID } \\
\#\end{array}$ & $\begin{array}{c}\text { Constant @ } \\
40^{\circ} \mathrm{C} \text { Upper } \\
\text { Bulb }\end{array}$ & $\begin{array}{c}\text { Constant @ } \\
40^{\circ} \mathrm{C} \text { Lower } \\
\text { Bulb }\end{array}$ & $\begin{array}{c}\text { Constant @ } \\
100^{\circ} \mathrm{C} \text { Upper } \\
\text { Bulb }\end{array}$ & $\begin{array}{c}\text { Constant @ } \\
100^{\circ} \mathrm{C} \text { Lower } \\
\text { Bulb }\end{array}$ & \multirow[t]{2}{*}{$\begin{array}{c}\text { Range of } \\
\text { Viscosities } \\
\text { (cSt) }\end{array}$} \\
\hline & & \multicolumn{4}{|c|}{ (cSt/s) } & \\
\hline 25 & 205 & 0.001419 & 0.001975 & 0.001430 & 0.001986 & 0.5 to 2 \\
\hline
\end{tabular}

Cannon-Fenske Reverse Flow Viscometer Tube

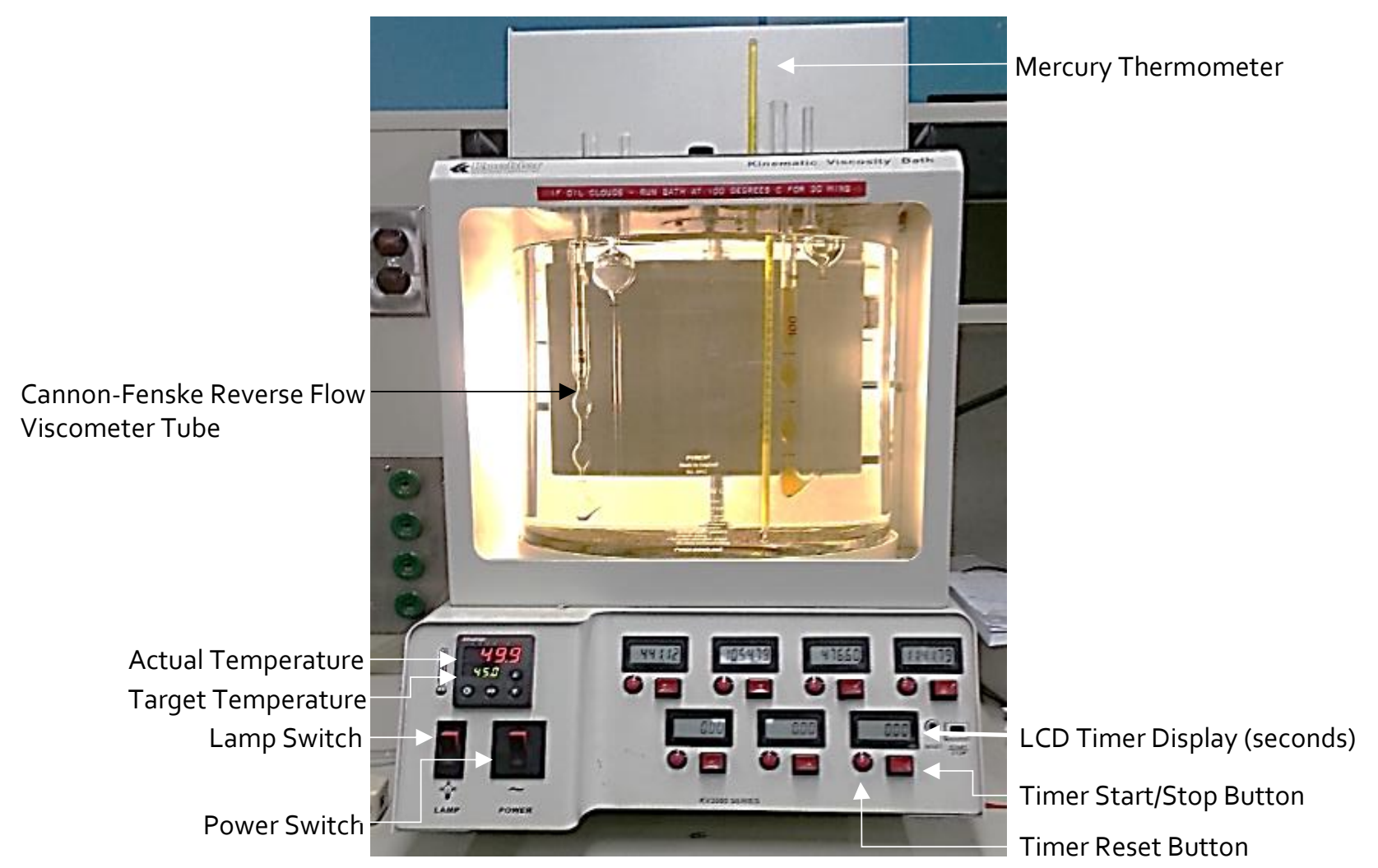

Figure 5: Koehler $\mathrm{KV}_{3} 000$ kinematic viscosity instrument

\section{Sources of Error}

Although efforts were made to ensure $\mathrm{KCl}$ and $\mathrm{NaCl}$ would dissolve uniformly into the distilled water by premixing them in solid form, it cannot be certain that they both dissolved at the same rate. If the salts did not dissolve at the same rates as previously assumed, then the ratio of $\mathrm{NaCl}$ to $\mathrm{KCl}$ in the solution would be skewed and could cause us to see a deviation in the viscosity measurements reported. Another point of concern in the experiment was precipitation of salt particulates in the viscometer tube. Although temperature was kept constant during testing precipitation resulted from
65-25 oC which decreases the solubility of the sample. Any excess solute at high temperatures would then precipitate out of the solvent as temperature is lowered. Due to the small diameter of the capillary vein, the presence of small floating salt particulates would change the behaviour of our ideal aqueous solution to a partial slurry-like fluid. Even though the co-saturated solution was changed half way through the temperature range to minimize precipitation it is believed that suspended salt particles may have had a mild effect on our reported data; the extent of how much is not known. 


\section{Conclusions}

The effect that co-saturation has on the kinematic viscosity of water is an important characteristic to understand. It is necessary to properly model the brines that are pumped from underground ore bodies in the process of solution mining. From existing literature, it is known that $\mathrm{NaCl}$ changes the viscosity of water by a factor of about 10 times more than $\mathrm{KCl}$. Due to the minimal effect that $\mathrm{KCl}$ has on viscosity it is observed that the concentration ratio curves of $\mathrm{NaCl}: \mathrm{KCl}$ look strikingly similar to the original $\mathrm{NaCl}$ curves found in literature. This similarity shows that in a solution where both $\mathrm{NaCl}$ and $\mathrm{KCl}$ are in a co-saturated state it is $\mathrm{NaCl}$ that contributes most to determining the viscosity of a salt brine.

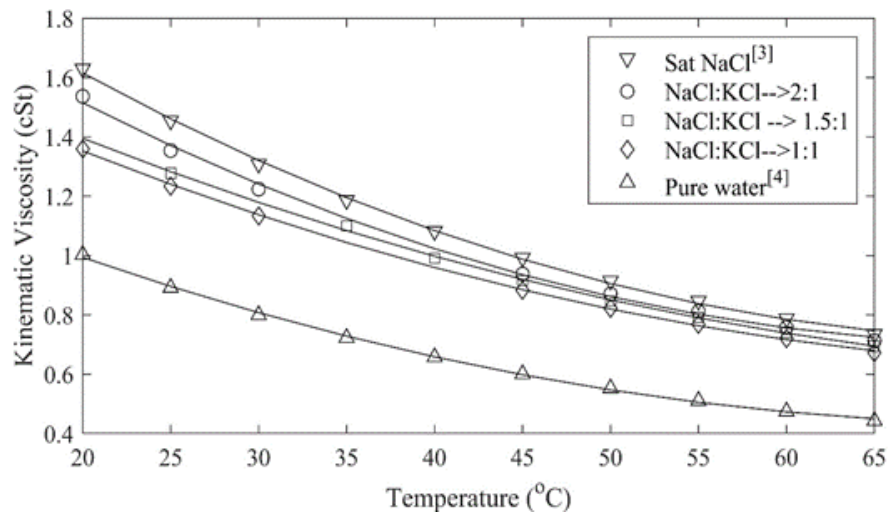

Figure 6: Viscosity of co-saturated aqueous $\mathrm{NaCl}$ and $\mathrm{KCl}$ solution vs temperature. Saturated $\mathrm{NaCl}$ and pure water values obtained from (Kestin, Khalifa, and Correia, 1981a).

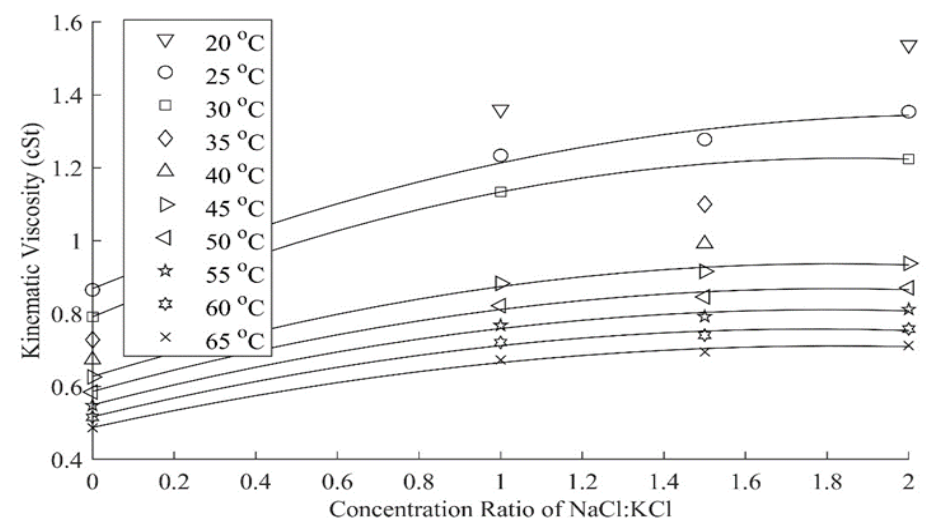

Figure 7: Kinematic viscosity of co-saturated solution of $\mathrm{NaCl}: \mathrm{KCl}$ vs concentration ratio. Zero point data collected from (Kestin, Khalifa, and Correia, 1981b). 


\section{References}

Canpotex. 2018. "What is Potash?" Accessed August 21, 2018. https://www.canpotex.com/our-potash/whatpotash.

Correia, R. J., J. Kestin, and H. E. Khalifa. "Measurement and Calculation of the Viscosity of Mixed Aqueous Solutions of $\mathrm{NaCl}$ and $\mathrm{KCl}$ in the Temperature Range $25-150^{\circ} \mathrm{C}$ and the Pressure Range o-30 MPa." Berichte Der Bunsengesellschaft Für Physikalische Chemie 83, no. 1 (1979): 20-24.

Gensource Potash Corp. n.d. "Potash Mining Methods."

Accessed August 23, 2018.

https://gensourcepotash.ca/potashmining/\#conventional-mining

Kay, Amanda. 2018."An Introduction to Potash Solution Mining." August 21. Accessed August 28, 2018. https://investingnews.com/daily/resourceinvesting/agriculture-investing/potash-investing/anintroduction-to-potash-solution-mining/.

Kestin, J., Khalifa, and Correia. 1981a."Tables of the Dynamic and Kinematic Viscosity of Aqueous $\mathrm{NaCl}$ Solutions in the Temperature Range $20-150^{\circ} \mathrm{C}$ and the Pressure Range 0.1-35 MPa." Journal of Physical and Chemical Reference Data 10, no. 1: 71-88.

Kestin, J., Khalifa, and Correia. 1981b. "Tables of the Dynamic and Kinematic Viscosity of Aqueous $\mathrm{KCl}$


the Pressure Range 0.1-35 MPa." Journal of Physical and Chemical Reference Data 10, no. 1: 57-70.

\section{Appendix - Raw Viscosity data}

A summary of the collected viscosity data is shown below in Table 3.

\begin{tabular}{|c|c|c|c|}
\hline \multirow{3}{*}{ Temperature $\left({ }^{\circ} \mathrm{C}\right)$} & \multicolumn{3}{|c|}{ Concentration Ratio $\mathrm{NaCl}: \mathrm{KCl}$} \\
\hline & $1: 1$ & $1.5: 1$ & $2: 1$ \\
\hline & \multicolumn{3}{|c|}{ Kinematic Viscosity (cSt) } \\
\hline 20 & 1.360 & - & 1.537 \\
\hline 25 & 1.234 & 1.278 & 1.354 \\
\hline 30 & 1.134 & - & 1.224 \\
\hline 35 & - & 1.100 & - \\
\hline 40 & - & 0.992 & - \\
\hline 45 & 0.883 & 0.916 & 0.938 \\
\hline 50 & 0.822 & 0.846 & 0.871 \\
\hline 55 & 0.768 & 0.792 & 0.812 \\
\hline 60 & 0.721 & 0.741 & $0.75^{8}$ \\
\hline 65 & 0.673 & 0.695 & 0.713 \\
\hline
\end{tabular}


